\title{
Os fatores de influência no comportamento do consumidor: um estudo em uma cooperativa agrícola do RS
}

\author{
The factors of influence on consumer behavior: a study in an agricultural cooperative \\ of RS
}

\begin{abstract}
Resumo
O presente artigo tem como objetivo analisar os principais fatores de influência no comportamento de compra do associado em uma Cooperativa Agrícola do Rio Grande do Sul. Metodologicamente, realizou-se uma pesquisa qualitativa e quantitativa, descritiva, por meio de um estudo de campo com uma amostra de 61 sócios escolhidos através de amostragem não probabilística por conveniência. O instrumento de coleta utilizado foi um questionário composto por treze questões fechadas. Os resultados obtidos apontaram que entre os fatores externos que mais exercem influência no comportamento de compra dos associados estão: a família, ambiente físico, cultura e, ainda, o propósito de compra e a classe social. Já em relação aos fatores internos identificou-se a motivação e as atitudes como influenciadores. Concluiu-se que, de modo geral, a maioria dos entrevistados está satisfeito com os produtos oferecidos pela Cooperativa e isso reflete na fidelização do associado existindo grande influência no seu comportamento de compra.
\end{abstract}

Palavras-chave: Comportamento; Consumidor; Influências; Fidelização.

\begin{abstract}
This article aims to analyze the main factors influencing the buying behavior enrolled in the Agricultural Cooperative of Rio Grande do Sul. Methodologically, we carried out a qualitative and quantitative, descriptive research through a field study with a sample of 61 members selected through non-probability convenience sampling. The instrument used was a questionnaire consisting of thirteen closed questions. The results showed that among the external factors that influence the buying behavior of associates are: family, physical environment, culture, and also the purpose of buying and social class. In relation to internal factors identified the motivation and attitudes as influencers. We concluded that, in general, the majority of respondents are satisfied with the products offered by the Cooperative and this is reflected in the loyalty of existing associated major influence on their buying behavior.
\end{abstract}

Keywords: Behavior; Consumer; Influences; Fidelity.

Recebido: 30/08/2014 Aceito: 01/10/2014

Simone Binotto ${ }^{1}$, Élio Sérgio Denardin² ${ }^{2}$ Flaviani Souto Bolzan Medeiros ${ }^{3}$, Juliana Andréia Rüdell Boligon ${ }^{4}$ e Flaubiane Figueredo Machado ${ }^{5}$

${ }^{1}$ Centro Universitário Franciscano, Bacharel em Administração - admmone@yahoo.com.br

${ }^{2}$ Centro Universitário Franciscano, Mestre em Filosofia - eliodenardin@hotmail.com

${ }^{3}$ Universidade Federal de Santa Maria, Mestranda no Programa de Pós-Graduação em Engenharia de Produção - flavianiadm@ gmail.com

${ }^{4}$ Centro Universitário Franciscano, Mestre em Engenharia de Produção - julianaboligon@unifra.br

${ }^{5}$ Centro Universitário Franciscano, Bacharel em Administração - flau_machado@hotmail.com 


\section{Introdução}

$\mathrm{N}$ o mundo em que se vive mutável e turbulento, onde as mudanças são aspectos constantes, o administrador precisa estar perfeitamente informado a respeito de forças e variáveis como a globalização, a competitividade, o desenvolvimento tecnológico e as informações, que têm grande poder no ambiente, para justificar as atividades de marketing.

Dentro dos segmentos do mercado o marketing desempenha um papel fundamental, como a regularização das relações econômicas de troca, onde equilibra a oferta e demanda. A atividade de marketing tem função de melhorar o padrão de vida, onde procura atender as necessidades e aspirações de seus consumidores que buscam sempre o melhor produto, isto é uma constante nos mercados competitivos, onde os desejos dos consumidores sofrem mudanças.

A força do marketing está em todo o lugar, pois na sociedade tudo que se consome é uma consequência de uma relação de troca que envolve produtos, preços distribuição e comunicação, assim o marketing permite que a vida aconteça com suas necessidades básicas e mais conforto (LAS CASAS, 2006).

Conforme Kotler e Keller (2007), o marketing conhece e entende os seus clientes, tornando os produtos adequados a esses por meio de processos que envolvem a criação, comunicação e a entrega de valor para os clientes e administra uma boa relação com eles, assim, a empresa se beneficia e também o seu mercado alvo, isso exige habilidade e trabalho, captando e fidelizando seus clientes.

Nesse sentido, o presente estudo tem como objetivo geral: identificar os principais fatores de influência no comportamento de compra do associado em uma Cooperativa Agrícola do Rio Grande do Sul. Para isso, estabeleceram-se como objetivos específicos: analisar as influências externas e internas no comportamento de compra; verificar a influência da satisfação do sócio em relação aos produtos da Cooperativa na compra; e conhecer o grau de fidelização do sócio e sua influencia na decisão de compra.

O estudo justifica-se por apresentar os fatores que influenciam na decisão de compra dos associados da Cooperativa levando em conta os fatores externos e internos deste comportamento, a satisfação dos associados ao produto e qual o grau de fidelidade a ela. Dessa forma, visa contribuir para a cooperativa tenha um conhecimento do que realmente influencia o comportamento dos seus associados, considerando que o consumidor está sempre buscando no mercado algo que satisfaça suas necessidades e seus desejos.

\section{Referencial teórico}

\subsection{Marketing}

Marketing é a ciência que dá o equilíbrio necessário às ações da empresa, balizando com isso os desejos e as necessidades do mercado-alvo, sem perder o controle da administração e seus objetivos (DUAILIBI; SIMONSEN JR., 2005).

Nesse sentido, Las Casas (2006) complementa que o marketing é o processo de planejamento e execução da concepção, preço, promoção e distribuição de ideias, bens e serviços organizacionais e eventos para criar trocas que venham satisfazer objetivos individuais e organizacionais.

Na visão de Kotler (1998), o marketing é um processo social e gerencial através do qual indivíduos e grupos obtêm aquilo que desejam e de que necessitam, criando e trocando produtos e valores uns com os outros.

A Figura 1 ilustra os conceitos centrais de marketing proposta por Tavares (2007).

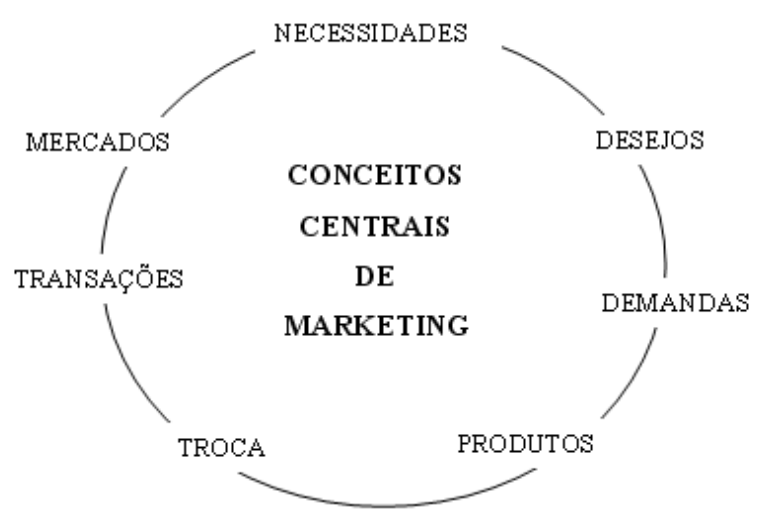

Figura 1 - Conceitos centrais de marketing Fonte: Tavares (2007, p. 1).

Verifica-se na Figura 1 que os conceitos centrais de marketing (necessidades, desejos, demandas, produtos, troca, transações e mercados) estão interligados numa relação causal direta, onde esta relação tem como princípio a base da construção da própria fundamentação teórica do marketing.

Portanto, no entendimento de Dias (2011), a função do marketing é entendida como processo de planejamento, execução e controle das estratégias e táticas de marketing, visando à otimização dos resultados para os clientes da empresa. Enquanto que para Cobra (1992), a função do marketing está relacionada com à satisfação dos desejos e necessidades dos consumidores e a compreensão das variáveis que o compõe.

Todavia, Leeflang (2011) enfatiza que embora o marketing tenha ganhado o seu lugar nas organizações existem grandes diferenças na forma como as mesmas são orientadas para o mercado, se organizam e operam 
suas atividades de marketing, bem como usam seus conhecimentos na área.

Muitas organizações adotam o conceito de marketing utilizando técnicas de segmentação, definindo estratégias de marketing e estabelecendo departamentos dedicados ao marketing em suas empresas (SHAH et al., 2006).

\subsection{Comportamento do consumidor}

O comportamento do consumidor é definido como as atividades físicas e mentais realizadas por clientes de bens de consumo e industriais que resultam em decisões e ações, como comprar e utilizar produtos e serviços, bem como pagar por eles (SHETH; MITTAL; NEWMAN, 2001).

No entendimento de Engel, Blackwell e Miniard (2000), o comportamento do consumidor consiste em uma atividade diretamente envolvida em obter, consumir e dispor de produtos e serviços, incluindo os processos decisórios que antecedem e sucedem estas ações. Conse- quentemente, é um assunto de interesse para qualquer empresa, seja qual for sua atividade ou função.

De acordo com Rocha (2004), além dos fatores culturais, sociais, pessoais e psicológicos, o comportamento de compra dos consumidores também sofre influência de fatores de natureza política, econômica, tecnológica, ambiental, assim como, fatores mercadológicos como o produto, o seu preço, a sua promoção e o seu ponto de distribuição.

Complementarmente, Mowen e Minor (2006) explicam que o processo de decisão do consumidor, envolvendo o reconhecimento de problemas antes de efetuar uma compra, passa por um processo de tomada de decisão sendo um processo construtivo, onde os consumidores tomam decisões continuamente e o processo empregado é influenciado pela dificuldade do problema.

Sob esse enfoque, Samara e Morsch (2006) acrescentam que o comportamento do consumidor pode ser visto como um processo decisório, lógico e estruturado de tomada de decisão, onde o processo de decisão de

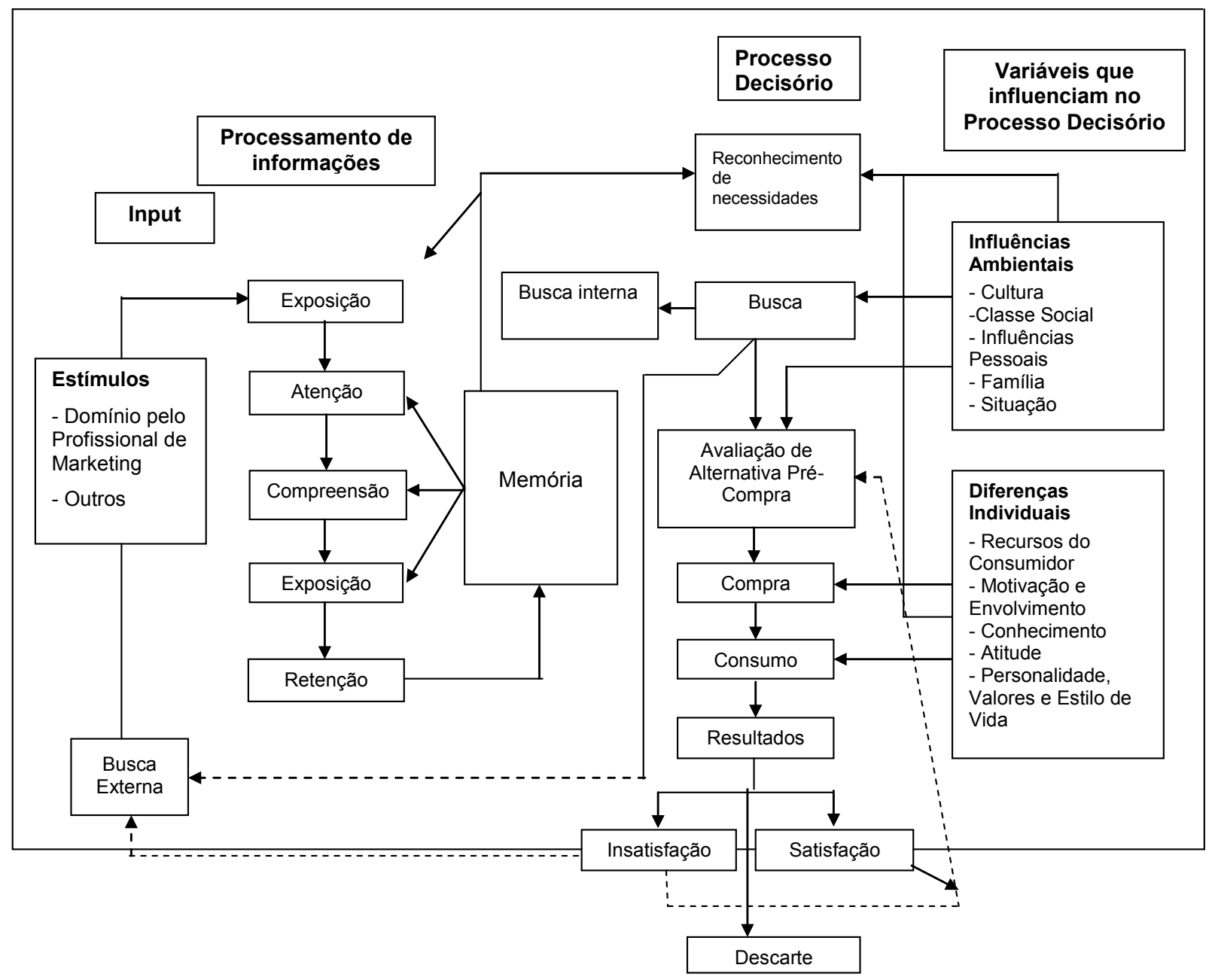

Figura 2 - Modelo do processo decisório de compra

Fonte: Engel, Blackwell e Miniard (2000, p. 101). 
compra envolve as seguintes etapas que se relacionam com o comportamento do consumidor: (1) primeiramente; há um reconhecimento da necessidade; (2) busca de informação; (3) quais as alternativas de produto e de compra; (4) decisão de compra; e (5) qual o comportamento pós-compra.

E ainda realiza-se uma avaliação do produto e da compra, pois o consumidor faz sua escolha para satisfazer sua necessidade. Os consumidores não tomam decisões no isolamento, são influenciados por fatores socioculturais como a cultura, subcultura, classe social, grupos de referência, a família e papéis desempenhados pelo homem e pela mulher na sociedade (SAMARA; MORSCH, 2006). O modelo visualizado na Figura 2 demonstra o processo de compra de bens e produtos sendo um resumo completo desta atividade desempenhada pelos consumidores.

Conforme pode ser observado na Figura 2, no entendimento de Engel, Blackwell e Miniard (2000), o processo de compra pelos consumidores tem quatro etapas, a saber: (1) inicia-se com os estímulos - inputs; (2) em seguida, passa para o processamento de informações; (3) na sequência, o processo decisório; e (4) na última etapa constam as variáveis que influenciam o processo decisório.

Sob essa perspectiva, a respeito da base de escolha, Francischelli (2009, p. 33) complementa que "o objeto para a tomada de decisão de compra é realizada, frequentemente, por meio da percepção de um ou mais atributos. Tais atributos são representados por "adjetivos", isto é, aquilo que o produto é, suas características, seus componentes e suas funções".

\subsubsection{Satisfação do consumidor}

Farias e Kovacs (2006) descrevem que a satisfação do consumidor é considerada um dos pilares do conceito de marketing. Atualmente, as empresas estão voltadas cada vez mais para o cliente e a maioria dessas compreende efetivamente a necessidade de satisfazer o consumidor, especialmente devido à concorrência cada vez mais acirrada no mercado.

Nesse sentido, Kotler e Keller (2007) explicam que a satisfação consiste em sensações de prazeres ou desapontamentos resultantes da comparação de desempenho percebido de um produto em relação às expectativas dos consumidores. Se o desempenho após a prestação do serviço não for alcançado e nem a sua perspectiva de consumo, ele ficará insatisfeito. A satisfação está relacionada com o sentimento na realização da compra e pode resultar em um cliente encantado e altamente satisfeito, assim, a retenção dos clientes torna-se fundamental para o sucesso da empresa.

Para Cobra (1997) satisfazer a necessidade do consumidor significa descobrir não apenas o que ele quer ou deseja para saciar suas necessidades, pois, a grande maioria das pessoas não sabe exatamente o que quer. A satisfação da compra está ligada a certas sensações que o consumidor imagina estar satisfazendo suas necessidades.

Complementarmente, Giese e Cote (2000) acrescentam que a satisfação dos consumidores tem sido definida como uma resposta emocional ou cognitiva baseada na experiência pessoal com um determinado produto e/ou serviço. Sob esse mesmo enfoque, Oliver (1993) explica que os consumidores costumam comparar suas expectativas pré-consumo e experiência pós-consumo para só depois ter sua resposta em termos de satisfação.

Deste modo, Dill, Duarte e Murcia (2006) complementam que a satisfação é uma avaliação global do consumidor em relação à sua experiência de consumo até o momento. Como a satisfação acumulada afeta diretamente o grau de lealdade do consumidor e, consequentemente, a rentabilidade do negócio, ela serve como um denominador comum para descrever as diferenças entre empresas e setores econômicos.

Quando a experiência pós-consumo é satisfatório, pode desencadear uma compra repetida e, assim, levar a lealdade para produtos e/ou marcas (GRUNERT, 2002).

Todavia, é importante ressaltar que a satisfação de um produto e/ou serviço pode ser diferente de um consumidor para o outro, isso porque depende da importância dada por cada um as diferentes características e atributos desse produto e/ou serviço (GUMMERUS, et al., 2004; HARRIS; GOODE, 2004).

\subsubsection{Fidelização do consumidor}

A fidelização do cliente também faz parte deste contexto. Tornar o cliente fiel faz parte da missão da empresa, criando valor e transformando clientes satisfeitos em clientes fiéis, mantê-los fieis acaba se tornando mais difícil para a empresa do que conquistá-los.

Conforme Mowen e Minor (2006), outro fator relacionado ao comportamento do consumidor é a fidelidade à marca, o consumidor estabelece um compromisso com ela e pretende continuar comprando-a no futuro. O consumidor muitas vezes se torna fiel pela qualidade que o produto oferece onde, muitas vezes, um pequeno aumento no preço não vai influenciar na compra.

As estratégias de marketing que envolvem promoção de vendas podem na realidade inibir a fidelidade à marca, ou seja, o cliente passa a comprar somente quando há promoção daquele produto. Fidelidade significa que a empresa está disposta a sacrificar pelo menos por um tempo seus interesses, pois, o sucesso da relação que se constrói a longo prazo é mais importante do que qualquer benefício imediato (MOWEN; MINOR, 2006).

A fidelização de clientes pode surgir a partir do desenvolvimento de um plano de satisfação e encantamento, sendo que, este gera um sentimento de ser encontrado o que queria, o necessário é sempre cumprir o que foi prometido ao cliente, transmitindo uma imagem de confiabilidade. A fidelidade está baseada na crença de 
cumprimento das promessas feitas pelo marketing sobre o produto ou serviço e a satisfação das necessidades do cliente. Esse ao procurar determinada marca ou empresa, está comprando também a esperança da satisfação de seus desejos, estando disposto a pagar pelo diferencial ou segurança do produto que procura. Desenvolver a fidelidade do cliente deve ser um compromisso de toda a empresa, sendo que todas as suas atividades devem servir ao objetivo de criar valor para o cliente, pois, ele é o foco da empresa e quando percebe que está sendo considerado, se sentirá motivado a retornar à empresa (CARDOSO, 2007).

\subsubsection{Influências no comportamento do consumi- dor}

As influências no comportamento do consumidor, segundo Schiffman e Kanuk (2000) podem ser externas e internas, a saber:

a) Influências externas sobre o comportamento do consumidor: essas forças desempenham um papel importante nas decisões tomadas pelos consumidores incluindo:

Fatores culturais: envolve a cultura, onde esta existe para satisfazer as necessidades das pessoas em seu meio social, proporcionando ordem, direção e orientação nas diversas etapas da solução do problema, as crenças, os costumes continuam sendo seguidos na sociedade desde que gerem satisfação, passadas de uma geração para outra. O consumidor possui uma subcultura de grupo, as pessoas de idades parecidas passam por experiências semelhantes, onde esses possuem valores, costumes comuns entre eles.

As influências situacionais também podem afetar o comportamento do consumidor, onde no ambiente físico tem as condições do local de compra, o clima, a localização geográfica, decoração da loja, são características facilmente observáveis da situação de compra. $\mathrm{O}$ ambiente social influencia o cliente pelos comentários e percepções feitos por outras pessoas que já estiveram no local, outros consumidores já são mais influenciados pelo tempo disponível para obter informações, tomar decisões, o tempo acaba sendo a prioridade.

Em um contexto cultural quando um produto deixa de ser aceito é porque um valor ou costume ao qual seu uso está relacionado não mais satisfaz as necessidades humanas, então a empresa deve rever o que está ofertando, onde os profissionais de marketing precisam estar atentos aos novos valores e costumes adotados (SILVA et al., 2011).

Fatores Sociais: Como o homem é um ser social, convive em grupos, onde esses podem moldar o comportamento de consumo dos indivíduos que os compõem, quanto maior for a intimidade entre os membros dos grupos e quanto maior a identificação entre eles, maior será a influência desse grupo no comportamento do indivíduo.

De acordo com Schiffman e Kanuk (2000), as pessoas avaliam suas atitudes, gerais ou específicas e seu comportamento associando-o a diferentes grupos de referência, como a família, amigos, classes sociais, etc. As famílias influenciam na compra desde o momento em que os pais definem os limites de seus filhos, assim a família está entre as mais importantes influências de grupo para a maioria dos consumidores, os membros da família com frequência influenciam as decisões de compra e fazem compras uns para os outros ou para a família como um todo. No que se refere à classe social é onde os indivíduos são classificados em termos de valor e prestígio, com base em sua riqueza, habilidade ou poder. Já os grupos de referência compartilham valores de sua cultura, subcultura e classe social. Os consumidores levam em conta ou consultam vários grupos quando tomam decisões de compra, as pessoas que influenciam os pensamentos, sentimentos e comportamentos dos consumidores.

b) Influências Internas sobre o Comportamento do Consumidor:

Fatores Psicológicos: o comportamento de consumo de uma pessoa pode ser influenciado por fatores psicológicos, conforme descritos no Quadro 1.

Motivação: quando uma pessoa deseja muito ter algo, mostra que ela está motivada; a motivação muitas vezes tem como ponto central o impulso ou o hábito do diadia. O consumidor não tem controle dos acontecimentos nem o que o influencia a efetuar a compra. O ser humano possui necessidades que o motivam a comprar, como necessidade de autorrealização, de estima, sociais, de segurança e necessidades fisiológicas.

Percepção: as pessoas costumam ver o mundo da sua maneira, muitas vezes deixando a realidade de lado, são apenas percepções, não o que realmente é, mas o que os consumidores pensam, o que realmente influência suas ações, seus hábitos de compra, onde o consumidor julga um produto com base em suas percepções, pode ser influenciado pela marca, embalagem, design, tamanho, cor, entre outros.

Aprendizagem: é o ato de aprender qualquer ofício, arte ou ciência, onde os indivíduos adquirem conhecimento e a experiência de compra e consumo.

Crenças e atitudes: é quando se acredita em algo, com ou sem fundamento. As crenças dos consumidores devem ser consideradas numa estratégia de marketing, no desenvolvimento do produto, no estabelecimento de preços, na determinação dos canais de marketing, na comunicação ou promoção. Podem-se levar em conta três questões subjacentes à atitude em relação a um objeto ela se baseia em algum conhecimento ou crença, onde são eles o conhecimento, o sentimento e a ação. 


\title{
Quadro 1 - Fatores Psicológicos
}

\begin{abstract}
Motivação: quando uma pessoa deseja muito ter algo, mostra que ela está motivada; a motivação muitas vezes tem como ponto central o impulso ou o hábito do dia-dia. $\mathrm{O}$ consumidor não tem controle dos acontecimentos nem o que o influencia a efetuar a compra. $\mathrm{O}$ ser humano possui necessidades que o motivam a comprar, como necessidade de autorrealização, de estima, sociais, de segurança e necessidades fisiológicas.
\end{abstract}

Percepção: as pessoas costumam ver o mundo da sua maneira, muitas vezes deixando a realidade de lado, são apenas percepções, não o que realmente é, mas o que os consumidores pensam, o que realmente influência suas ações, seus hábitos de compra, onde o consumidor julga um produto com base em suas percepções, pode ser influenciado pela marca, embalagem, design, tamanho, cor, entre outros.

Aprendizagem: é o ato de aprender qualquer ofício, arte ou ciência, onde os indivíduos adquirem conhecimento e a experiência de compra e consumo.

Crenças e atitudes: é quando se acredita em algo, com ou sem fundamento. As crenças dos consumidores devem ser consideradas numa estratégia de marketing, no desenvolvimento do produto, no estabelecimento de preços, na determinação dos canais de marketing, na comunicação ou promoção. Podem-se levar em conta três questões subjacentes à atitude em relação a um objeto ela se baseia em algum conhecimento ou crença, onde são eles o conhecimento, o sentimento e a ação.

Fonte: Adaptado Schiffman e Kanuk (2000).

As organizações precisam entender como seus atuais e potenciais consumidores pensam, trabalham e se divertem, onde a organização revela estudos necessários, estruturando a tomada de decisão para o melhor lançamento e desenvolvimento de novos produtos no mercado, onde se torna cada vez mais importante conhecer os consumidores de diferentes costumes, culturas e personalidades. O comportamento do consumidor envolve a aquisição, no consumo e na disposição de mercadorias, serviços, experiências e ideias, sendo o processo de troca um elemento fundamental.

\section{Metodologia}

A metodologia refere-se ao conjunto de métodos e técnicas usadas em uma investigação (MICHEL, 2009). Dessa forma, no caso da presente pesquisa foi realizado um estudo qualitativo e quantitativo quanto à natureza, do tipo descritivo quanto aos objetivos, através de uma pesquisa de campo com os associados de uma Cooperativa no que se refere aos procedimentos técnicos.

Sobre a pesquisa quantitativa, Roesch (2006) explica que esta procura obter informações sobre determinada população, como quantos membros da organização possuem a mesma opinião sobre determinado assunto. $\mathrm{Na}$ abordagem qualitativa, o pesquisador tem por finalidade mostrar as opiniões e sugestões de determinado grupo de indivíduos em relação a um fenômeno específico, visando propiciar sua descrição e explorá-lo minuciosamente para melhor compreendê-lo (MARCONI; LAKATOS, 2008).

Em relação à pesquisa descritiva, segundo Gil (2006) esse tipo de pesquisa tem como objetivo primordial a descrição das características de determinada população ou fenômeno, ou, então, o estabelecimento de relações entre variáveis.

Destaca-se que a Cooperativa Agrícola pesquisada possui aproximadamente 4.000 sócios, sendo extraída uma amostra de 61, através de uma amostragem não probabilística, por conveniência. O instrumento de coleta de dados utilizado foi um questionário elaborado pelos autores de acordo com os objetivos da pesquisa tendo como base o referencial teórico abordado no estudo. $\mathrm{O}$ referido instrumento era composto por 24 perguntas fechadas divididas da seguinte forma: as 7 primeiras questões visavam identificar o perfil do associado; na sequências as 10 seguintes eram sobre as influências dos fatores externos; em seguida, as outras 3 referiam-se as influências dos fatores internos; e as últimas 4 questões, por sua vez, tinham como propósito verificar a satisfação e fidelização do associado.

Para a coleta de dados optou-se por duas maneiras 
diferenciadas, ou seja, uma presencial com os sócios da área urbana entrevistados pessoalmente pelos autores; e a outra foi à entrega dos questionários e posterior devolução dos mesmos preenchidos para os associados que residem no interior do município em função da extensão da área rural.

Foram selecionadas duas comunidades interioranas nas quais estão localizadas duas escolas estaduais com maior fluxo de alunos, onde esses levaram os questionários para seus pais que são associados e sendo recolhidos alguns dias depois. Após a coleta, os dados foram tabulados com o auxílio do software Sphinx Léxica - V5 e analisados sob a ótica qualitativa.

\section{Análise e discussão dos resultados}

\subsection{Perfil dos associados entrevistados}

Constatou-se que $52,5 \%$ dos entrevistados são do genêro masculino e $47,5 \%$ pertencem ao genêro feminino. Percebe-se que a Cooperativa possui associados de ambos os genêros, o que explica a amostra ser bastante semelhante.

No que se refere à faixa etária dos associados, observou-se que $21,3 \%$ possuem entre 21 e 30 e com o mesmo percentual (21,3\%) possuem mais de 50 anos, $19,7 \%$ situam-se entre 31 a 40 anos e entre 41 a 50 anos encontram-se $37,7 \%$, portanto, sendo abordado associados de todas as idades.

Em relação à escolaridade, percebe-se que grande parte dos sócios 31,2\% possuem 1o grau incompleto e $11,5 \%$ completo, totalizando $42,7 \%$, já $27,9 \%$ dos sócios concluíram o 2 o grau e $13 \%$ possuem 2 o grau incompleto e, com um mesmo percentual de $8,2 \%$ situam-se no 30 grau incompleto e 3 o grau completo.

Observa-se que a maioria dos sócios entrevistados moram na cidade $(72,1 \%)$, e apenas $27,9 \%$ residem no interior e, ainda, que 39,4\% deles já são sócios da Cooperativa há mais de 15 anos, enquanto que 23\% de 1 a 5 anos, outros $18 \%$ fazem parte entre 6 a 10 anos, $13 \%$ entre 11 a 15 anos e apenas 6,6\% são sócios até 1 ano.

Quanto aos locais em que o cliente costuma comprar, apresentando citações múltiplas, ou seja, aquirem produtos em diversos postos da Cooperativa, destacando-se que $93,4 \%$ dos sócios compram no mercado, 57,4\% na ferragem, $21,3 \%$ na loja de confecções e apenas $8,2 \%$ compram na loja de esporte.

Já em relação à frequência que o associado compra na Cooperativa, $37,7 \%$ responderam uma vez por semana, $24,6 \%$ uma vez por mês, $18 \%$ compram a cada quinze dias e $19,7 \%$ mais de uma vez por semana.

Diante desses resultados torna-se relevante trazer a recomendação de Gonçalves (2007), a respeito da importância de se traçar o perfil do consumidor e se dedicar a ele para atender suas necessidades e expectativas, pois muitas empresas acabam perdendo-o por não desenvolverem critérios de preferência, e tampouco sabem o perfil dos seus clientes.

\subsection{Influência dos fatores externos no com- portamento de compra}

Constatou-se na Tabela 1 que, em relação aos fatores externos, a família possui média influência no comportamento de compra, ou seja, $36 \%$; já um percentual de $32,8 \%$ dos sócios avalia como grande a influência; outros $23 \%$ consideram pequena; e apenas $8,2 \%$ acreditam que a família não possui influência na compra. Esse resultado reforça a ideia dos autores Schiffman e Kanuk (2000), de que a família está entre as mais importantes influências de grupo para a maioria dos consumidores nas decisões de compra.

Em seguida, observa-se que 36\% dos sócios ponderam pequena a influência do grupo no seu comportamento de compra; enquanto que 31,2\% consideram que não há nenhuma influência; já outros $27,9 \%$ dos entrevistados avaliam como média; e apenas $4,9 \%$ admitem ser grande. Portanto, pode-se dizer que os sócios não consideram que o grupo de referência influencia no ato da compra.

Na sequência, a partir dos dados obtidos, contata-se que $50,8 \%$ dos sócios julgam que a classe social possui média influência no comportamento de compra; já $23 \%$ consideram grande a sua influência; enquanto que 21,3\% ponderam como pequena; e tão somente $4,9 \%$ acreditam que não influencia. Assim, percebe-se que a classe social é um dos fatores externos que influencia na compra.

No próximo item, quando indagados sobre a influência do ambiente social no comportamento de compra, nota-se que $45,9 \%$ dos sócios a consideram média; com um mesmo percentual de $24,6 \%$ julgam que não há e atribuem uma pequena influência; e somente $4,9 \%$ avaliam como grande.

Em seguimento, na análise da influência da cultura no comportamento de compra, verifica-se que $44,2 \%$ dos sócios entendem que possui média influência; outros $23 \%$ consideraram pequena; já $21,3 \%$ admitem exercer grande influência; e 11,5\% julgam que a cultura não possui nenhuma influência na compra.

De modo geral, dos fatores analisados até então, identificou-se que os sócios da Cooperativa recebem uma influência classificada como média oscilando para grande, vindo ao encontro do que afirma Samara e Morsch (2006), ou seja, que os consumidores não tomam decisões sozinhos, mas são influenciados por aspectos socioculturais, classe social, grupos de referência, a família e papéis desempenhados pelo homem e pela mulher na sociedade.

Pelo estudo na Tabela 1, quando questionados sobre a influência da propaganda no comportamento de compra, constata-se que 39,3\% dos sócios avaliam que 
Tabela 1 - Influência dos fatores externos no comportamento de compra

\begin{tabular}{|c|c|c|}
\hline Influência da FAMÍLIA & Frequência & Percentual \\
\hline Nenhuma & 5 & $8,2 \%$ \\
\hline Pequena & 14 & $23,0 \%$ \\
\hline Média & 22 & $36,0 \%$ \\
\hline Grande & 20 & $32,8 \%$ \\
\hline Total & 61 & $100 \%$ \\
\hline Influência do GRUPO DE REFERÊNCIA & Frequência & Percentual \\
\hline Nenhuma & 19 & $31,2 \%$ \\
\hline Pequena & 22 & $36,0 \%$ \\
\hline Média & 17 & $27,9 \%$ \\
\hline Grande & 3 & $4,9 \%$ \\
\hline Total & 61 & $100 \%$ \\
\hline Influência da CLASSE SOCIAL & Frequência & Percentual \\
\hline Nenhuma & 3 & $4,9 \%$ \\
\hline Pequena & 13 & $21,3 \%$ \\
\hline Média & 31 & $50,8 \%$ \\
\hline Grande & 14 & $23,0 \%$ \\
\hline Total & 61 & $100 \%$ \\
\hline Influência do AMBIENTE SOCIAL & Frequência & Percentual \\
\hline Nenhuma & 15 & $24,6 \%$ \\
\hline Pequena & 15 & $24,6 \%$ \\
\hline Média & 28 & $45,9 \%$ \\
\hline Grande & 3 & $4,9 \%$ \\
\hline Total & 61 & $100 \%$ \\
\hline Influência da CULTURA & Frequência & Percentual \\
\hline Nenhuma & 7 & $11,5 \%$ \\
\hline Pequena & 14 & $23,0 \%$ \\
\hline Média & 27 & $44,2 \%$ \\
\hline Grande & 13 & $21,3 \%$ \\
\hline Total & 61 & $100 \%$ \\
\hline Influência da PROPAGANDA & Frequência & Percentual \\
\hline Nenhuma & 16 & $26,2 \%$ \\
\hline Pequena & 14 & $23,0 \%$ \\
\hline Média & 24 & $39,3 \%$ \\
\hline Grande & 7 & $11,5 \%$ \\
\hline Total & 61 & $100 \%$ \\
\hline Influência do AMBIENTE FÍSICO & Frequência & Percentual \\
\hline Nenhuma & 4 & $6,6 \%$ \\
\hline Pequena & 8 & $13,0 \%$ \\
\hline Média & 21 & $34,5 \%$ \\
\hline Grande & 28 & $45,9 \%$ \\
\hline Total & 61 & $100 \%$ \\
\hline Influência do PROPÓSITO DE COMPRA & Frequência & Percentual \\
\hline Nenhuma & 8 & $13,0 \%$ \\
\hline Pequena & 13 & $21,3 \%$ \\
\hline Média & 26 & $42,7 \%$ \\
\hline Grande & 14 & $23,0 \%$ \\
\hline Total & 61 & $100 \%$ \\
\hline Influência do ESTADO DE ESPÍRITO & Frequência & Percentual \\
\hline Nenhuma & 18 & $29,4 \%$ \\
\hline Pequena & 14 & $23,0 \%$ \\
\hline Média & 20 & $32,8 \%$ \\
\hline Grande & 9 & $14,8 \%$ \\
\hline Total & 61 & $100 \%$ \\
\hline
\end{tabular}


possui média influência; já outros $26,2 \%$ consideram que não influencia; $23 \%$ consideram como pequena sua influência; e 11,5\% admitem ser grande o seu poder de influenciar a compra. Para a maioria $(50,8 \%)$ há uma influência de média para grande.

Em relação à influência do ambiente físico, percebe-se que $45,9 \%$ dos associados consideram que possui grande influência na compra; enquanto 34,5\% julgam como média; outros $13 \%$ como sendo pequena; e apenas $6,6 \%$ julgam que não exerce nenhuma influência.

Considerando que o ambiente físico exerce influência no comportamento de compra do associado na escolha do estabelecimento para realizar suas compras, recomendase à Cooperativa dar uma atenção especial nesse ponto.

A respeito da influência do propósito de compra 42,7\% dos sócios ponderaram essa influência como sendo média; 23\% consideram como sendo grande; $21,3 \%$ julgam como pequena; enquanto que apenas 13\% acreditam que não possui nenhuma influência. Portanto, pode-se dizer que boa parte dos sócios da Cooperativa avalia que o propósito de compra tanto para uso pessoal como doméstico exerce influência no comportamento de compra.

Verifica-se que a influência do estado de espírito no comportamento de compra dos associados para $32,8 \%$ dos entrevistados é média a influência do item; 29,4\% acreditam que não possui influência; enquanto que outros $23 \%$ pensam ser pequena; e 14,8\% admitem ser grande essa influência no momento da compra.

No que se refere à influência da quantidade de tempo para realizar a compra, observa-se que 36\% dos sócios consideram pequena a influência, 32,8\% pensam ser média, $16,4 \%$ consideram grande e $14,8 \%$ acham que esse fator não possui nenhuma influência. Dessa forma, pode-se dizer que a maioria dos sócios considera que a quantidade de tempo possui uma pequena e média influência no comportamento de compra.

Pode-se dizer que não é uma tarefa simples entender o comportamento do consumidor e suas respectivas variáveis, pois apesar das empresas ouvirem os seus clientes e desenvolverem produtos e/ou serviços que venham atender suas necessidades e expectativas, nem sempre o consumidor revela seus desejos e anseios mais profundos (FRANCISCHELLI, 2009).

\subsection{Influência dos fatores internos no com- portamento de compra}

Pelos dados apresentados na Tabela 2, observa-se que a maioria dos sócios recebe uma grande (50,8\%) e média (23\%) influência da motivação na compra, que somadas atinge um percentual de $73,8 \%$; outros $21,3 \%$ consideram pequena e 4,9\% alegam que não influencia.

A respeito da percepção $32,8 \%$ dos sócios entrevistados acreditam que a percepção possui média influência, com um mesmo percentual de $26,2 \%$ julgam como pequena e grande respectivamente e, $14,8 \%$ pensam que não possui nenhuma influência. Complementarmente, Kotler e Armstrong (2007, p.123) definem a percepção

Tabela 2 - Influência dos fatores internos no comportamento de compra

\begin{tabular}{|c|c|c|}
\hline Influência da MOTIVAÇÃO & Frequência & Percentual \\
\hline Nenhuma & 3 & $4,9 \%$ \\
\hline Pequena & 13 & $21,3 \%$ \\
\hline Média & 14 & $23,0 \%$ \\
\hline Grande & 31 & $50,8 \%$ \\
\hline Total & 61 & $100 \%$ \\
\hline Influência da PERCEPÇÃO (cor, marca) & Frequência & Percentual \\
\hline Nenhuma & 9 & $14,8 \%$ \\
\hline Pequena & 16 & $26,2 \%$ \\
\hline Média & 20 & $32,8 \%$ \\
\hline Grande & 16 & $26,2 \%$ \\
\hline Total & 61 & $100 \%$ \\
\hline Influência das ATITUDES & Frequência & Percentual \\
\hline Nenhuma & 3 & $4,9 \%$ \\
\hline Pequena & 4 & $6,6 \%$ \\
\hline Média & 22 & $36,0 \%$ \\
\hline Grande & 32 & $52,5 \%$ \\
\hline Total & 61 & $100 \%$ \\
\hline
\end{tabular}

Fonte: Elaborado pelos autores com base nos dados da pesquisa. 
como "o processo pelo qual uma pessoa seleciona, organiza e interpreta as informações para formar uma visão significativa do mundo".

Pela análise na Tabela 2, percebe-se que a maioria dos sócios entende que as atitudes possuem grande influência na compra; enquanto que 36\% consideram média; já 6,6\% julgam como pequena; e somente 4,9\% pensam que não exerce nenhuma influência.

As influências constatadas na pesquisa confirmam o exposto pelos autores Schiffman e Kanuk (2000), ou seja, que o ser humano possui necessidades que o motivam a comprar, tais como: autorrealização, de estima, sociais, de segurança e fisiológicas, assim como, a percepção e as atitudes no comportamento de compra.

\subsection{Satisfação e fidelização dos associados da Cooperativa}

Percebe-se, na Tabela 3, que a maioria dos sócios está satisfeito com os produtos oferecidos pela Cooperativa, ou seja, $68,9 \%$; outros $14,8 \%$ estão pouco satisfeitos; já $13 \%$ afirmam estar muito satisfeitos; e apenas 3,3\% afiram estarem insatisfeitos.

Em posse desses dados, visualiza-se que a maioria dos sócios da Cooperativa está satisfeito com os produtos, desse modo, pode-se dizer que os mesmos estão satisfazendo o associado e, assim, atendendo suas necessidades.

Sobre a influência da satisfação no comportamento de compra constatou-se que 93,4\% dos sócios acreditam que a influência é média para grande, 45,9\% e 47,5\% respectivamente. Com os mesmos percentuais de 3,3\% consideram que é pequena e até que não possui influencia no ato da compra. Nesse sentido, Kotler (1998) explica que a satisfação de compra é o resultado da diferença entre o desempenho percebido pelo consumidor e suas expectativas anteriores de compra de determinado produto e/ou serviço.

Pela análise na Tabela 3 nota-se que a maioria dos sócios considera que o grau de fidelização exerce uma influência média no momento da compra (73,8\%); outros $23 \%$ acreditam que é elevado; enquanto que somente $3,2 \%$ julgam como sendo baixo.

No que se refere à influência da fidelização na compra para grande parte dos sócios entrevistados (45,9\%) é média; já outros $31,1 \%$ consideram grande; $16,4 \%$ alegam ser pequena; e só 6,6\% pensam que a fidelização não possui nenhuma influência.

Sob essa perspectiva, reforça as palavras de Cardoso

Tabela 3 - Satisfação e fidelização dos sócios

\begin{tabular}{lcc}
\hline \multicolumn{1}{c}{ Grau de satisfação em relação aos produtos oferecidos } & Frequência & Percentual \\
\hline Muito satisfeito & 8 & $13,0 \%$ \\
Satisfeito & 42 & $68,9 \%$ \\
Pouco satisfeito & 9 & $14,8 \%$ \\
Insatisfeito & 2 & $3,3 \%$ \\
Total & 61 & $100 \%$ \\
\hline \multicolumn{1}{|c}{ Influência da satisfação no comportamento de compra } & Frequência & Percentual \\
\hline Nenhuma & 2 & $3,3 \%$ \\
Pequena & 2 & $3,3 \%$ \\
Média & 28 & $45,9 \%$ \\
Grande & 29 & $47,5 \%$ \\
Total & 61 & $100 \%$ \\
\hline Grau de fidelização do associado em relação à Cooperativa & Frequência & Percentual \\
\hline Elevado & 14 & $23,0 \%$ \\
Médio & 45 & $73,8 \%$ \\
Baixo & 2 & $3,2 \%$ \\
Total & 61 & $100 \%$ \\
\hline Influência da fidelização no comportamento de compra & Frequência & Percentual \\
\hline Nenhuma & 4 & $6,6 \%$ \\
Pequena & 10 & $16,4 \%$ \\
Média & 28 & $45,9 \%$ \\
Grande & 19 & $31,1 \%$ \\
Total & 61 & $100 \%$ \\
\hline
\end{tabular}

Fonte: Elaborado pelos autores com base nos dados da pesquisa. 
(2007), ao expor que a fidelização de clientes pode surgir a partir do desenvolvimento de um plano de satisfação e encantamento, sendo que, este gera um sentimento de ser encontrado o que queria, o necessário é sempre cumprir o que foi prometido ao cliente, transmitindo uma imagem de confiabilidade.

\section{Considerações finais}

Atualmente, na área de marketing o comportamento do consumidor vem sendo considerado um fator essencial para o crescimento e sucesso de toda e qualquer empresa, independentemente do seu porte ou ramo de atuação no mercado. Nesse sentido, com base no estudo realizado foi possível identificar os fatores que exercem influência no comportamento de compra do associado em uma Cooperativa Agrícola do Rio Grande do Sul.

Sendo assim, em relação aos fatores externos analisados observa-se que entre os que mais influenciam estão: a família, o ambiente físico, cultura, como também o propósito de compra e a classe social. Em contrapartida, o que menos influencia, por sua vez, é o grupo de referência.

Considera-se relevante destacar que o ambiente físico exerce de média a grande influência no comportamento de compra do associado (80,4\%). Deste modo, sugerese à Cooperativa dar uma maior atenção nesse sentido. Já a propaganda é um fator do comportamento que a Cooperativa poderá explorar mais, assim os sócios irão obter cada vez mais informações sobre a mesma.

A respeito dos fatores internos, destacou-se a motivação que considera necessidades e desejos dos clientes e atitudes referentes ao conhecimento do produto e, com um menor destaque, a percepção relacionada à marca e cor dos produtos.

Outro aspecto identificado refere-se à satisfação do associado que, de modo geral, os entrevistados estão satisfeitos com os produtos oferecidos pela Cooperativa, esta satisfação faz com que os sócios voltem a comprar no estabelecimento. Tais dados refletem a fidelização por parte do associado fazendo com que exista uma grande influência no seu comportamento de compra.

Ao findar o estudo, acredita-se que novas pesquisas possam ser realizadas a fim de contribuir ainda mais ao tema. Sendo assim, recomenda-se que além desse estudo seja aplicado novamente dentro de certo período de tempo na mesma Cooperativa analisada, com o propósito de comparar os resultados obtidos e efetuar as devidas mudanças, caso seja necessário. Também se sugere replicar essa pesquisa em outras cooperativas e empresas de diferentes ramos de atividade considerando a importância dos fatores que exercem influência no comportamento de compra do consumidor.

\section{Referências}

CARDOSO, C. Fidelização de clientes. 2007. Disponível em: <http://noticia.ttp://noticia.truenet.com.br/ desafio21/newstorm.notitia.apresentacao.ServletDeNoticia?codigoDaNoticia=1200\&dataDoJornal=atual>. Acesso em: 10 ago. 2013.

COBRA, M. Administração de marketing. 2. ed. São Paulo: Atlas, 1992.

- Marketing básico: uma perspectiva brasileira. 4. ed. São Paulo: Atlas, 1997.

DIAS, S. R. (Org.). Gestão de marketing. 2. ed. São Paulo: Saraiva 2011.

DILL, P.; DUARTE, C.; MURCIA, F. D. Contemplando a subjetividade na mensuração do nível de satisfação do cliente: uma abordagem experimental utilizando os conceitos da Lógica Fuzzy. In: ENCONTRO DA ANPAD, 30., Salvador, 2006. Anais... Salvador: EnANPAD, 2006. CD-ROM.

DUAILIBI, R.; SIMONSEN JR., H. Criatividade \& marketing. São Paulo: Pearson Makron Books, 2005.

ENGEL, J. F.; BLACKWELL, R. D.; MINIARD, P. W. Comportamento do consumidor. 8. ed. Rio de Janeiro: Livros Técnicos e Científicos Editora S.A, 2000.

FARIAS, S. A; KOVACS, M. H. Esforço do consumidor, estratégias de redução do risco percebido e satisfação: proposição de um esquema teórico para o comércio eletrônico. In: ENCONTRO DA ANPAD, 30., Salvador, 2006. Anais... Salvador: EnANPAD, 2006. CD-ROM.

FRANCISCHELLI, P. A importância da marca no processo de decisão de compra de calçados esportivos para a população de baixa renda. 2009. 120 f. Dissertação (Mestrado em Administração) - Programa de Mestrado Executivo em Gestão Empresarial da Fundação Getulio Vargas, Rio de Janeiro, 2009.

GIESE, J. L.; COTE, J. A. Defining consumer satisfaction. Academy of Marketing Science Review, v. 4, n. 2, 2000.

GIL, A. C. Métodos e técnicas de pesquisa social. 5. ed. São Paulo: Atlas, 2006.

GONÇALVES, H. J. Fidelização de clientes. 2007. 61 f. Curso de Especialização (Especialista em Gestão de Negócios Financeiros) - Programa de Pós-Gradua- 
ção em Administração da Universidade Federal do Rio Grande do Sul, Porto Alegre, 2007.

GRUNERT, K. G. Current issues in the understanding of consumer food choices. Trends in Food Science \& Technology, v. 13, p. 275-285, 2002.

GUMMERUS, J.; LILJANDER, V.; PURA, M.; RIEL, A. V. Customer loyalty to content-based Web sites: the case of an online health-care service. Journal of Services Marketing, v. 18, n. 3, p. 175-186, 2004.

HARRIS, L. C.; GOODE, M. M. H The four levels of loyalty and the pivotal role of trust: a study of online service dynamics. Journal of Retailing, v. 80, n. 2, p. 139-158, 2004.

KOTLER, P. Administração de marketing: análise, planejamento, implementação e controle. 5. ed. São Paulo: Atlas, 1998.

KOTLER, P.; KELLER, K. L. Administração de marketing: a bíblia do marketing. 12. ed. São Paulo, 2007.

LAS CASAS, A. L. Administração de marketing: conceitos, planejamento e aplicações à realidade brasileira. São Paulo: Atlas, 2006.

LEEFLANG, P. Paving the way for "distinguished marketing". International Journal of Research in Marketing, v. 28, n. 2, p. 76-88, 2011.

MARCONI, M. de A.; LAKATOS, E. M. Técnicas de pesquisa. 7. ed. São Paulo: Atlas; 2008.

MICHEL, M. H. Metodologia e pesquisa científica em ciências sociais: um guia prático para acompanhamento da disciplina e elaboração de trabalhos monográficos. 2. ed. São Paulo: Atlas, 2009.

MOWEN, J. C.; MINOR, M. S. Comportamento do consumidor. São Paulo: Prentice Hall, 2006.

OLIVER, R. Cognitive, affective, and attribute bases of the satisfaction response. Journal of Consumer Research, v. 20, p. 418-430, 1993.

ROCHA, L. C. Orientação para clientes. Rio de Janeiro: Senac Nacional, 2004.

ROESCH, S. M. A. Projetos de estágio e de pesquisa em administração. 3. ed. São Paulo: Atlas, 2006.

SAMARA, B. S.; MORSCH. M. A. Comportamento do consumidor: conceitos e causos. São Paulo: Pearson Prentice Hall, 2006.
SCHIFFMAN, L. G.; KANUK, L. L. Comportamento do consumidor. 6. ed. Rio de Janeiro: LTC, 2000.

SHAH, D.; RUST, R. T.; PARASURAMAN, A.; STAELIN, R.; DAY, G. S. The path to customer centricity. Journal of Service Research, v. 9, n. 2, p. 113-124, 2006.

SHETH, J. N.; MITTAL, B.; NEWMAN, B. I. Comportamento do cliente: indo além do comportamento do consumidor. São Paulo: Atlas, 2001.

SILVA, D. B. dos S.; MARCHESINI, F. R. de A.; OLIVEIRA, J. A. F. de; SÁ, L. C. S. de. Fundamentos de marketing. 4. ed. Rio de Janeiro: FGV, 2011.

TAVARES, F. Marketing: conceitos, tipos, objetivos e análise de desempenho. 2007. Disponível em: <http://www.portaldomarketing.com.br/Artigos/ Marketing_Conceitos_Tipos_Objetivos_e_analise_ de_desempenho.htm>. Acesso em: 20 ago. 2013. 
